\author{
JOURNAL OF DINDA \\ Kelompok Keahlian Rekayasa Data \\ Institut Teknologi Telkom Purwokerto \\ ISSN Media Elektronik: -
}

Vol. 1 No. 2 (2021) 77 - 81

\title{
Sistem Pendukung Keputusan Prediksi Harga Rumah Kost untuk Mahasiswa IT Telkom Purwokerto Menggunakan Metode Fuzzy Tsukamoto Berbasis Web
}

\author{
Ummi Athiyah $^{1}$, Arnelka Hananta ${ }^{2}$, Taufik Maulidi ${ }^{3}$, Vico Meylana Eka Putra ${ }^{4}$, Theo Felix Harianto Purba ${ }^{5}$ \\ Elisabeth Angeline Wilhelmina Bakowatun ${ }^{6}$ \\ ${ }^{1,6}$ Sains Data, Fakultas Informatika, Institut Teknologi Telkom Purwokerto \\ 2,3,4,5Teknik Informatika, Fakultas Informatika, Institut Teknologi Telkom Purwokerto \\ ${ }^{1}$ ummiathiyah@ittelkom-pwt.ac.id, ${ }^{2} 17102004 @$ ittelkom-pwt.ac.id, ${ }^{3} 17102118 @$ ittelkom-pwt.ac.id, \\ ${ }^{4} 17102143 @$ ittelkom-pwt.ac.id, ${ }^{5} 17102166 @$ ittelkom-pwt.ac.id, ${ }^{6} 20110003 @$ ittelkom-pwt.ac.id
}

\begin{abstract}
Purwokerto City is a developing city located in the southwestern part of Central Java Province. Purwokerto is known as the city of students in Central Java. It is not wrong if many newcomers choose to continue their studies at the favorite universities in this city. One of the universities in this city is the Telkom Purwokerto Institute of Technology. With so many newcomers who want to continue their studies in this city. Of course, you need a place to live like a boarding house. Each boarding house has different facilities and also has varying prices, making it difficult for newcomers to choose the boarding house. So a decision support system is needed to help students of the Telkom Purwokerto Institute of Technology to make the right decision in predicting the price of a boarding house when choosing a boarding house according to the existing criteria and funds using the Fuzzy Tsukamoto method.
\end{abstract}

Keywords: Boarding House, Fuzzy Tsukamoto, Telkom Purwokerto Institute of Technology

\begin{abstract}
Abstrak
Kota Purwokerto merupakan sebuah kota berkembang yang terletak di bagian barat daya Provinsi Jawa Tengah. Purwokerto mendapat julukan sebagai kota pelajar di Jawa Tengah, tidak salah jika banyak pendatang yang memilih untuk melanjutkan studinya ke perguruan tinggi favorit di kota ini. Salah satu perguruan tinggi di kota ini yaitu Institut Teknologi Telkom Purwokerto. Dengan banyaknya para pendatang yang ingin melanjutkan studinya di kota ini. Tentunya membutuhkan tempat untuk ditinggali seperti rumah kost. Setiap rumah kost memiliki fasilitas yang berbeda dan juga memiliki harga yang bervariasi sehingga membuat para pendatang kesulitan dalam memilih rumah kost tersebut. Maka diperlukan suatu sistem pendukung keputusan untuk membantu mahasiswa Institut Teknologi Telkom Purwokerto untuk mengambil keputusan yang tepat dalam memprediksi harga rumah kost pada saat memilih rumah kost sesuai dengan kriteria dan dana yang ada menggunakan metode Fuzzy Tsukamoto.
\end{abstract}

Kata kunci: Rumah Kost, Fuzzy Tsukamoto, Institut Teknologi Telkom Purwokerto

(C) 2021 Jurnal DINDA

\section{Pendahuluan}

Kota Purwokerto merupakan sebuah kota berkembang yang terletak di bagian barat daya Provinsi Jawa Tengah, Purwokerto sendiri merupakan Ibukota Kabupaten Banyumas. Meskipun Purwokerto hanyalah sebatas Ibukota Kabupaten, kota ini digolongkan sebagai Ibukota Kabupaten yang maju dan perkembangannya yang pesat dari tahun ke tahun.
Purwokerto mendapat julukan sebagai kota pelajar di Jawa Tengah, tidak salah jika banyak pendatang yang memilih untuk melanjutkan studinya ke perguruan tinggi favorit di kota ini. Salah satu perguruan tinggi di kota ini yaitu Institut Teknologi Telkom Purwokerto. Institut Teknologi Telkom Purwokerto merupakan perguruan tinggi swasta dan satu-satunya institut di Jawa Tengah yang fokus pada pengembangan ilmu pengetahuan berbasis teknologi informasi pada bidang Healthcare, 
Agro-Industry, Tourism, dan Small Medium Enterprise (HATS) [3].

Dengan banyaknya para pendatang yang ingin melanjutkan studinya di kota ini. Tentunya membutuhkan tempat untuk ditinggali seperti rumah kost. Sedangkan banyaknya rumah kost di Purwokerto begitu banyak dan setiap rumah kost memiliki fasilitas yang berbeda dan juga memiliki harga yang bervariasi sehingga membuat para pendatang kesulitan dalam memilih rumah kost tersebut. Dikarenakan rumah kostnya nanti sesuai dengan kriterianya dan juga dengan mempertimbangkan dana yang ada.

Banyak hal yang menjadi pertimbangan dalam memilih kost misalnya ada yang memilih kost dengan lokasi yang strategis seperti dekat dengan kampus, tempat makan, fasilitas kost, ataupun tempat hiburan. Ada yang memilih kost dengan lingkungan yang mendukung dan kondusif untuk belajar atau ada juga yang lebih suka keramaian. Selain itu harga sewa dan fasilitas kost juga menjadi pertimbangan mahasiswa dalam memilih rumah kost [7].

Berdasarkan dari permasalahan tersebut maka penulis mengambil judul "Sistem Pendukung Keputusan Prediksi Harga Rumah Kost Untuk Mahasiswa Institut Teknologi Telkom Purwokerto Menggunakan Metode Fuzzy Tsukamoto Berbasis Web" harapannya penelitian ini dapat mempermudah mahasiswa Institut Teknologi Telkom Purwokerto dalam memprediksi harga rumah kost sesuai dengan kriteria yang diinginkan dengan sebuah sistem pengambilan keputusan menggunakan metode fuzzy tsukamoto.

\section{Metode Penelitian}

Metode penelitian yang digunakan untuk membuat sistem pengambilan keputusan untuk Keputusan Prediksi Harga Rumah Kost Untuk Mahasiswa Institut Teknologi Telkom Purwokerto menggunakan analisis deskriptif, yang merupakan metode yang bertujuan untuk mendapatkan gambaran yang jelas tentang hal-hal yang diperlukan. Metodologi ini dibagi menjadi dua, yaitu, pengumpulan data dan pengembangan perangkat lunak sebagai berikut :

a. Pengumpulan Data

Metode pengumpulan data yang digunakan dalam penelitian ini adalah sebagai berikut:
1). Studi
Literatur
Mempelajari buku-buku acuan dan literatur yang berhubungan dengan materi dalam penulisan laporan serta melakukan pengamatan.

2). Observasi

Observasi adalah metode mengumpulkan data dengan melakukan penelitian dan tinjauan langsung terhadap masalah yang diambil, sehingga penulis dapat menemukan apa yang dapat ditemukan dalam sistem pendukung keputusan untuk Prediksi Harga Rumah Kost Untuk Mahasiswa Institut Teknologi Telkom Purwokerto Menggunakan Metode Fuzzy Tsukamoto Berbasis Web.

b. Pengembangan Perangkat Lunak

Metode pengembangan sistem yang digunakan untuk sistem pendukung keputusan ini yaitu :

1). Merancang dan Membuat Prototype berbasis web.

2). Uji Coba Sistem.

\subsection{Ruang Lingkup}

Untuk mempermudah penulisan penelitian ini dan agar lebih terarah dan berjalan dengan baik, maka perlu kiranya dibuat suatu batasan masalah. Adapun ruang lingkup yang akan dibahas dalam penulisan,yaitu :

a. Penelitian menggunakan data kriteria yang menjadi fasilitas umum sebuah rumah kost.

b. Penelitian ini hanya menggunakan data dan jarak rumah kost menuju IT Telkom Purwokerto.

2.2. Landasan Teori

a. Sistem Pendukung Keputusan

Sistem pendukung keputusan atau Computer Based Decision Support System (DSS) merupakan salah satu bagian dari sistem informasi yang berguna untuk meningkatkan efektifitas pengambilan keputusan [5]. Sistem pendukung keputusan dimaksudkan untuk menjadi alat bantu bagi para pengambil keputusan untuk memperluas kapabilitas mereka, namun tidak untuk menggantikan penilaian mereka [2].

b. Rumah Kost

Rumah kost merupakan hunian sewa yang diperuntukkan untuk tempat singgah sementara [1]. Rumah kost menawarkan sebuah kamar atau tempat untuk ditinggali dengan sejumlah pembayaran tertentu untuk setiap periode tertentu.

c. Metode Fuzzy Tsukamoto

Metode Tsukamoto adalah perluasan dari penalaran monoton. Pada metode Tsukamoto, setiap konsekuen pada aturan yang berbentuk IF-THEN harus direpresentasikan dengan suatu himpunan fuzzy dengan fungsi keanggotaan yang monoton. Sebagai hasilnya, output hasil inferensi dari tiap- tiap aturan diberikan secara tegas (crisp) berdasarkan $\alpha$-predikat (fire 
strength). Hasil akhirnya diperoleh dengan 3.3. Fungsi Keanggotaan menggunakan rata-rata terbobot [4].

a. Jarak

\section{Hasil dan Pembahasan}

3.1 Analisis Sistem

Dalam tahap analisis sistem, di tahap ini bertujuan untuk mengidentifikasi masalah dan kebutuhan dalam membangun sebuah sistem, agar diperoleh hasil yang sesuai dengan apa yang dibutuhkan.
a. Analisis
Sistem
Yang
Berjalan

Dalam tahapan ini sistem yang sedang berjalan bertujuan untuk mengetahui lebih jelas bagaimana kerja sistem tersebut. Dengan begitu kelebihan dan kekurangan sistem dapat diketahui.

b. Analisa Proses

Dalam proses ini mahasiswa yang ingin mengetahui prediksi harga rumah kost yang ada di purwokerto, dengan memasukan beberapa nilai di beberapa variabel di kolom yang sudah disediakan.

3.2. Penyelesaian Dengan Fuzzy Tsukamoto

Dengan melakukan pengambilan data kriteria rumah kost yang dimana data tersebut berisi jarak, fasilitas rumah kost, ukuran kamar, dan harga rumah kost berdasarkan pilihan yang peneliti tentukan.

Tabel 1. Kriteria Rumah Kost

\begin{tabular}{cc}
\hline Kriteria dan Fasilitas & Range \\
\hline Jarak & $0-40 \mathrm{~km}$ \\
Fasilitas & $0 \%-100 \%$ \\
Ukuran Kamar & $0-20 \mathrm{~m}^{2}$ \\
\hline Tabel 2. Contoh kasus inferensi Fuzzy \\
\hline Variabel Input & Nilai Input \\
\hline Jarak & $1 \mathrm{~km}$ \\
Fasilitas & $20 \%$ \\
Ukuran Kamar & $4 \mathrm{~m} 2$ \\
\hline
\end{tabular}

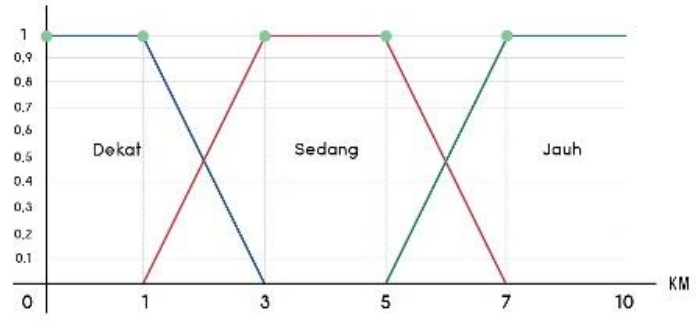

Derajat keanggotaan Jarak Dekat

$$
\begin{aligned}
& 1 \quad ; w \leq 1 \\
& \frac{(3-w)}{(3-1)} ; 1 \leq w \leq 3 \\
& 0 \quad ; w \geq 3
\end{aligned}
$$

Derajat keanggotaan Jarak Sedang

$$
\begin{aligned}
& 1 \quad ; 3 \leq w \leq 5 \\
& \frac{(w-1)}{(3-1)} ; 1 \leq w \leq 3 \\
& \frac{(7-w)}{(7-5)} ; 5 \leq w \leq 7 \\
& 0 \quad ; w \leq 1 \text { atau } w \geq 7
\end{aligned}
$$

Derajat keanggotaan Jarak Jauh

$$
\begin{array}{ll}
0 & ; w \leq 5 \\
\frac{(w-3)}{(7-5)} ; & 5 \leq w \leq 7 \\
1 & ; w \geq 7
\end{array}
$$

b. Ukuran Kamar

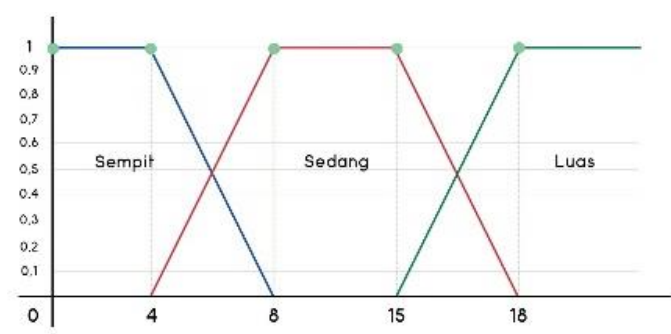

Derajat keanggotaan Ukuran Kamar Sempit :

$$
\begin{array}{ll}
1 \quad ; y \leq 4 \\
\frac{(8-y)}{(8-4)} ; 4 \leq y \leq 8 \\
0 \quad ; y \geq 8
\end{array}
$$

Derajat keanggotaan Ukuran Kamar Sedang

$0 \quad ; \mathrm{y} \leq 4$ atau $\mathrm{y} \geq 18$

Journal of DINDA (Data Science, Information Technology, and Data Analytics) Vol . 1 No. 2 (2021) $77-81$ 


$$
\begin{aligned}
& \frac{(y-4)}{(8-4)} ; 4 \leq y \leq 8 \\
& \frac{(18-y)}{(18-15)} ; 15 \leq y \leq 18 \\
& 1 \quad ; 8 \leq \mathrm{y} \leq 15
\end{aligned}
$$

Derajat keanggotaan Ukuran Kamar Luas

$$
\begin{aligned}
& 0 ; y \leq 15 \\
& \frac{(y-15)}{(18-15)} ; 15 \leq y \leq 18 \\
& 1 \quad ; y \geq 18
\end{aligned}
$$

c. Fasilitas

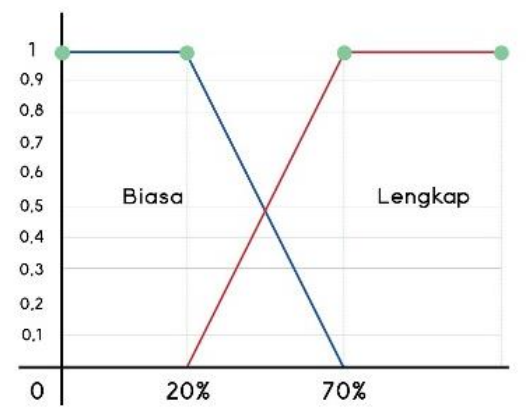

Derajat keanggotaan Fasilitas Biasa

$$
\begin{aligned}
& 1 ; \quad ; v \leq 20 \\
& \frac{(70-v)}{(70-20)} ; 20 \leq v \leq 70 \\
& 0 \quad ; \mathrm{v} \geq 70
\end{aligned}
$$

Derajat keanggotaan Fasilitas Lengkap

$$
\begin{aligned}
0 & ; \mathrm{v} \leq 20 \\
\frac{(v-20)}{(70-20)} ; & 20 \leq v \leq 70 \\
1 \quad ; \mathrm{v} \geq & \geq 70
\end{aligned}
$$

d. Harga

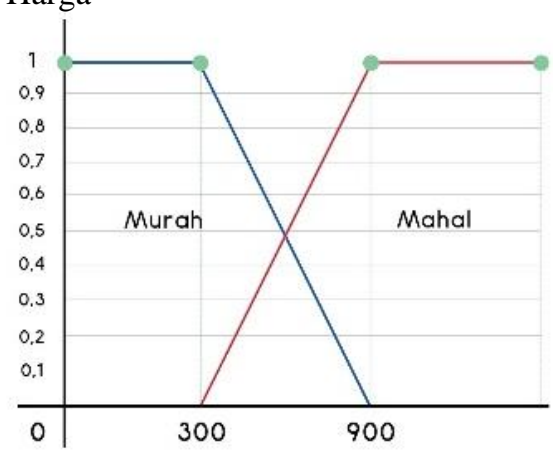

Derajat keanggotaan Harga Murah

$$
\begin{aligned}
& 1 \quad ; \mathrm{x} \leq 300 \\
& \frac{(900-x)}{(900-300)} ; 300 \leq x \leq 900 \\
& 0 \quad ; \mathrm{x} \geq 900
\end{aligned}
$$

Derajat keanggotaan Harga Mahal

$0 \quad ; \mathrm{x} \leq 300$

$$
\begin{aligned}
& \frac{(x-300)}{(900-300)} ; 300 \leq x \leq 900 \\
& 1 \quad ; x \geq 900
\end{aligned}
$$

\subsection{Pembentukan Aturan}

Pembentukan Aturan Fuzzy, Dari dua variabel input dan sebuah variabel output yang telah didefinisikan. Variabel tersebut berisi jarak, fasilitas rumah kost, ukuran kamar, dan harga rumah kost berdasarkan pilihan yang peneliti tentukan.

1). Jika fasilitas BIASA dan ukuran SEMPIT dan jarak DEKAT maka harga MAHAL

2). Jika fasilitas BIASA dan ukuran SEMPIT dan jarak SEDANG maka harga MURAH.

3). Jika fasilitas BIASA dan ukuran SEMPIT dan jarak JAUH maka harga MURAH.

4). Jika fasilitas BIASA dan ukuran SEDANG dan jarak DEKAT maka harga MAHAL.

5). Jika fasilitas BIASA dan ukuran SEDANG dan jarak SEDANG maka harga MURAH.

6). Jika fasilitas BIASA dan ukuran SEDANG dan jarak JAUH maka harga MURAH.

7). Jika fasilitas BIASA dan ukuran LUAS dan jarak DEKAT maka harga MAHAL.

8). Jika fasilitas BIASA dan ukuran LUAS dan jarak SEDANG maka harga MURAH.

9). Jika fasilitas BIASA dan ukuran LUAS dan jarak JAUH maka harga MURAH.

10). Jika fasilitas LENGKAP dan ukuran SEMPIT dan jarak DEKAT maka harga MAHAL.

11). Jika fasilitas LENGKAP dan ukuran SEMPIT dan jarak SEDANG maka harga MAHAL.

12). Jika fasilitas LENGKAP dan ukuran SEMPIT dan jarak JAUH maka harga MURAH.

13). Jika fasilitas LENGKAP dan ukuran SEDANG dan jarak DEKAT maka harga MAHAL.

14). Jika fasilitas LENGKAP dan ukuran SEDANG dan jarak SEDANG maka harga MAHAL.

15). Jika fasilitas LENGKAP dan ukuran SEDANG dan jarak JAUH maka harga MURAH.

16). Jika fasilitas LENGKAP dan ukuran LUAS dan jarak DEKAT maka harga MAHAL.

17). Jika fasilitas LENGKAP dan ukuran LUAS dan jarak SEDANG maka harga MAHAL.

18). Jika fasilitas LENGKAP dan ukuran LUAS dan jarak JAUH maka harga MURAH.

\subsection{Implementasi}

Dalam Tahap implementasi ini merupakan suatu tindakan atau pelaksanaan dari rencana yang sudah disusun secara matang dan terperinci.

a. Tampilan aplikasi

Dibawah ini merupakan tampilan aplikasi prediksi harga rumah kost. Tampilan aplikasi ini

Journal of DINDA (Data Science, Information Technology, and Data Analytics) 
disajikan beberapa inputan berupa jarak kost, [4] ukuran kamar, dan list fasilitas.

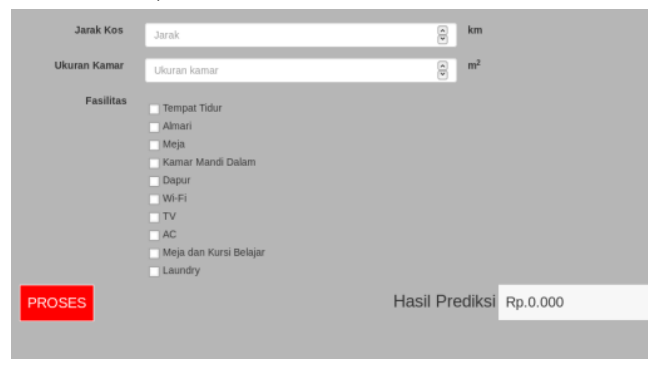

b. Tampilan Hasil Perhitungan

Dibawah ini adalah hasil perhitungan berdasarkan inputan menggunakan metode Tsukamoto. Hasil prediksi akan ditampilkan berupa perkiraan harga rumah kost.

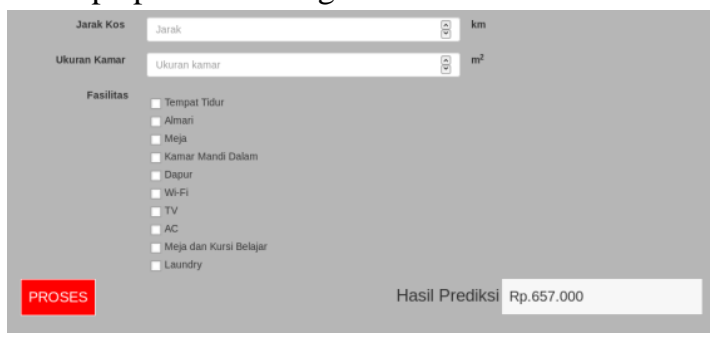

\section{Kesimpulan}

a. Kesimpulan

Penelitian ini berfokus pada rumah kost yang akan digunakan oleh mahasiswa IT Telkom Purwokerto. Penelitian ini menggunakan metode tsukamoto dan berbasis web.

b. Saran

Pada penelitian ini hanya menggunakan data acak. Maka untuk penelitian yang lebih baik kedepannya, diharapkan menggunakan data yang riil atau nyata agar penelitian dapat berjalan dengan baik.

\section{Daftar Rujukan}

[1] D. Gunawan and E. Nugroho, "Sistem Informasi Sewa Rumah Kost Dan Rumah Kontrakan Berbasis Web Di Surakarta," Informatika, vol. 2, no. 1, p. 242608, 2015.

[2] Arisandi, M. I. Sarita, and L. O. H. S. Sagala, "Sistem penunjang keputusan pemilihan hotel di kota kendari menggunakan metode," J. Semant., vol. 2, no. 1, pp. 331-340, 2016.

[3] "Profil Institut Teknologi Telkom Purwokerto", ittelkom-pwt.ac.id, 13 Januari 2021, https://ittelkom-pwt.ac.id/profil/.
A. A. Caraka, H. Haryanto, D. P. Kusumaningrum, S. Astuti, F. I. Komputer, and U. D. Nuswantoro, "Logika Fuzzy Menggunakan Metode Tsukamoto Untuk Prediksi Perilaku Konsumen Di Toko Bangunan," Techno.COM, vol. 14, no. 4, pp. 255265, 2015, [Online]. Available: http://publikasi.dinus.ac.id/index.php/technoc/arti cle/view/970.

[5] Murti, T., Abdillah, L. A., \& Sobri, M. (2015). Sistem penunjang keputusan kelayakan pemberian pinjaman dengan metode fuzzy tsukamoto. 252256.

[6] Susanti, N. (2013). Penentuan Harga Jual Produk Pisau pada UKM" Bareng Jaya" Menggunakan Jaringan Syaraf Tiruan. Jurnal SIMETRIS, 4(1).

[7] Matematika, J., Mahasiswa, K., Faktor, A., \& Indonesia, D. (2012). FAKTOR-FAKTOR YANG MEMENGARUHI KEPUTUSAN MAHASISWA DALAM MEMILIH RUMAH KOST. 1(1), 25-31.

[8] Muchlas and T. Sutikno, "Prediksi harga saham berbasis web dengan sistem inferensi fuzi tsukamoto," Pros. Semin. Nas. Apl. Teknol. Inf. 2007 (SNATI 2007), vol. 2007, no. Snati, pp. D27D31, 2007.

[9] A. Wantoro, K. Muludi, and Sukisno, "Penerapan Logika Fuzzy pada Sistem Pendukung Keputusan Penentuan Kelayakan Kualitas Telur Bebek," Jutis, vol. 7, no. 1, pp. 1-6, 2019.

[10] A. P. Ardyanti, I. I. Adnyana, and I. N. Purnama, "Sistem Pakar Untuk Deteksi Penyakit Pada Ternak Babi Dengan Menggunakan Metode Fuzzy Tsukamoto," J. Teknol. Inf. dan Komput., vol. 4, no. 2, pp. 141-149, 2018, doi: 10.36002/jutik.v4i2.546.

[11] M. A. Rahmadani and A. Septiarini, "Penerapan Fuzzy Tahani Pada Sistem Pendukung Keputusan Pemilihan Pembelian Rumah Di Kota Samarinda 1)," J. Inform. Mulawarman Ed. Juli, vol. 8, no. 2, pp. 56-60, 2013.

[12] Suryati, M. Ricky Hikmawan, R. G. (2016) 'Politeknik Negeri Sriwijaya', SISTEM PENDUKUNG KEPUTUSAN PEMBERIAN BEASISWA DI POLITEKNIK NEGERI SRIWIJAYA MENGGUNAKAN METODE FUZZY LOGIC TSUKAMOTO Suryati, 7(July 2016), p. 55. 